\title{
NoTE
}

\section{Adult-onset hypogonadotropic hypogonadism caused by aberrant expression of aromatase in an adrenocortical adenocarcinoma}

\author{
Andrew Advani ${ }^{1), 2)}$, Sarah J. Johnson ${ }^{3)}$, Moira R. Nicol ${ }^{4)}$, Georgia Papacleovoulou ${ }^{4)}$, Dean B. Evans ${ }^{5)}$, \\ Suresh Vaikkakara ${ }^{6)}$, J. Ian Mason")*, and Richard Quinton"1),7)* \\ ${ }^{1)}$ Department of Endocrinology, The Newcastle upon Tyne NHS University Hospitals Foundation Trust, Newcastle upon Tyne, UK \\ ${ }^{2)}$ Keenan Research Centre in the Li Ka Shing Knowledge Institute, St. Michael's Hospital and University of Toronto, Toronto, ON, \\ Canada \\ ${ }^{3)}$ Department of Cellular Pathology, The Newcastle upon Tyne NHS University Hospital Foundation Trust, Newcastle upon Tyne, UK \\ ${ }^{4)}$ Reproductive \& Developmental Sciences Division, Centre for Reproductive Biology, The Queen's Medical Research Institute, \\ University of Edinburgh, Edinburgh, UK \\ ${ }^{5)}$ Novartis Institute for BioMedical Research, Basel, Switzerland \\ ${ }^{6)}$ Sri Venkateswara Institute of Medical Sciences, Tirupati, Andhra Pradesh, India \\ ${ }^{7}$ Institute for Human Genetics, University of Newcastle upon Tyne, UK
}

\begin{abstract}
Estrogen-secreting adrenal cancers are extremely rare, with feminizing symptoms attributed to aromatase expression in the adrenal tumor. We describe a case of hypogonadotropic hypogonadism as a consequence of aberrant aromatase expression in a patient with adrenocortical adenocarcinoma. A 54 year-old man presented with a two month history of gynecomastia and reduced libido. Endocrine biochemistry at presentation showed hypogonadotropic hypogonadism ( $\mathrm{LH} 2.4 \mathrm{U} / \mathrm{L}, \mathrm{FSH}<1.0 \mathrm{IU} / \mathrm{L}$, testosterone $2.8 \mathrm{nmol} / \mathrm{L})$ with increased serum estrone $\left(\mathrm{E}_{1}, 821 \mathrm{pmol} / \mathrm{L}\right)$ and estradiol $\left(\mathrm{E}_{2}, 797 \mathrm{pmol} / \mathrm{L}\right)$ and subclinical ACTH-independent hypercortisolism (serum cortisol post $1 \mathrm{mg}$ overnight dexamethasone suppression test, $291 \mathrm{nmol} / \mathrm{L}$ ). A right adrenal mass was identified on CT scanning and the patient underwent an open adrenalectomy. Post-operative evaluation showed normalization of serum levels of $\mathrm{E}_{1}(95 \mathrm{pmol} / \mathrm{L}), \mathrm{E}_{2}$ (109 pmol/L), testosterone (11.4 nmol/L), LH(4.1 U/L) and FSH(5.9 IU/L), and of cortisol dynamics. Immunohistochemistry of the adrenal cancer confirmed aberrant expression of aromatase in most, although not all, carcinoma cells. Transcripts associated with utilization of promoters II, I.1 and I.3 were prominently represented in the tumor aromatase mRNA. This case highlights that clinical features of feminizing adrenocortical carcinomas can be secondary to estrogen production by aberrantly transcribed and translated aromatase within the tumor. Even in males, gonadotropin secretion is subject to predominantly estrogen-mediated feedback-inhibition. The diagnosis of adrenocortical adenocarcinoma should be considered in men presenting with low testosterone and gonadotropins, particularly in the presence of feminizing features.
\end{abstract}

Key words: Aromatase, Hypogonadotropic hypogonadism, Adrenocortical adenocarcinoma, Gynecomastia, Testosterone

\begin{abstract}
ADRENOCORTICAL adenocarcinoma is a rare malignancy with an incidence of approximately 1-2 per million population [1, 2]. Although clinical evidence of steroid excess occurs in approximately $60 \%$ of cases [1], feminizing symptoms secondary to estrogen-secretion are extremely uncommon [3, 4]. Microsomal

Received Feb. 16, 2010; Accepted Apr. 16, 2010 as K10E-046 Released online in J-STAGE as advance publication May 13, 2010

Correspondence to: Dr. Richard Quinton, Department of Endocrinology, Royal Victoria Infirmary, Newcastle upon Tyne, NE1 4LP. UK. E-mail: richard.quinton@ncl.ac.uk

*These authors contributed equally to this work.
\end{abstract}

cytochrome P450 aromatase (aromatase) is the final and rate-limiting step in estrogen biosynthesis and is the product of the CYP19 gene. The enzyme catalyses the conversion of C19 steroids, androstenedione, testosterone and $16 \alpha$-hydroxyandrostenedione, to estrone $\left(E_{1}\right)$, estradiol $\left(E_{2}\right)$ and estriol respectively in a tissuedependent manner, according to substrate availability. In adult humans, aromatase is expressed in ovaries, placenta and adipose tissue with low levels in testes and brain [5]. In the past, feminizing symptoms of adrenocortical carcinomas had been attributed to peripheral aromatization of adrenal androgens [6]. However, 
Table 1 Endocrine investigations pre- and post-operatively.

\begin{tabular}{|c|c|c|c|}
\hline & Pre-operative & Post-operative & Reference range \\
\hline Estrone $\left(\mathrm{E}_{1}\right)(\mathrm{pmol} / \mathrm{L})$ & 821 & 95 & $0-330$ \\
\hline Estradiol $\left(\mathrm{E}_{2}\right)(\mathrm{pmol} / \mathrm{L})$ & 797 & 109 & $0-180$ \\
\hline Testosterone (nmol/L) & 2.8 & 11.4 & $9-25$ \\
\hline SHBG (nmol/L) & 55 & 20 & $13-71$ \\
\hline Calculated free testosterone (pmol/L) & 37 & 297 & $215-760$ \\
\hline LH (U/L) & 2.4 & 4.1 & $3.0-13.0$ \\
\hline FSH (IU/L) & $<1.0$ & 5.9 & $1.3-9.2$ \\
\hline 11-Deoxycortisol (nmol/L) & 19.8 & 7.8 & $5.0-12.1$ \\
\hline $\begin{array}{l}\text { Cortisol (nmol/L) } \\
\text { (post-1mg overnight dexamethasone) }\end{array}$ & 291 & $<24$ & $<50$ \\
\hline Urinary free cortisol (nmol/24h) & $269 \& 466$ & 63 & $(0-320)$ \\
\hline ACTH (9am) (ng/L) & 7 & -- & $(0-47)$ \\
\hline DHEA sulfate $(\mu \mathrm{mol} / \mathrm{L})$ & 1.9 & -- & $(1.1-10.9)$ \\
\hline Androstenedione $\left(\Delta_{4}\right)(\mathrm{nmol} / \mathrm{L})$ & 5.7 & -- & $(<13)$ \\
\hline $17 \alpha$-hydroxyprogesterone (nmol/L) & 3.3 & -- & $(0-10)$ \\
\hline Aldosterone (pmol/L) & 169 & -- & $(100-450)$ \\
\hline
\end{tabular}

recent case reports have demonstrated local aromatase mRNA and activity in the tumorous adrenal tissue [7].

We present the case of a man with a short history of gynecomastia and loss of libido secondary to an estrogen-producing adrenocortical carcinoma. Immunostaining of the adrenal tumor revealed the presence of aromatase protein in cytoplasmic aggregates suggesting abnormal production and processing of the enzyme.

\section{Case report}

A 54 year-old man presented with a 2 month history of bilateral gynecomastia and reduced libido. There was no history of exposure to exogenous estrogens, androgen antagonists or of excess alcohol consumption. Physical examination revealed symmetrical $4 \mathrm{~cm}$ $\mathrm{x} 4 \mathrm{~cm}$ gynecomastia and diminished testicular volume (15 and $12 \mathrm{~mL}$ ). He was found to have profound biochemical hypogonadotropic hypogonadism, associated with markedly elevated estrogen levels and abnormal cortisol dynamics (Table 1). Contrast-enhanced computerized tomographic scanning identified an approximately $6-6.5 \mathrm{~cm}$ relatively homogenous enhancing right adrenal mass which demonstrated areas of necrosis on magnetic resonance imaging. Plasma metanephrines were normal [normetadrenaline $(\mathrm{pmol} / \mathrm{L})$
246 and 220 (reference range, 0-1000), metadrenaline (pmol/L) 167 and 155 (reference range, 0-600)].

The patient underwent open adrenalectomy and an enlarged and encapsulated 145g (70x70x65mm) right adrenal gland was removed without complication. Intra-operatively, there was no evidence of metastatic disease. Histological examination revealed that the gland was mostly occupied by a nodule composed of predominantly eosinophilic cells with diffuse architecture, focal confluent necrosis, moderate nuclear pleomorphism, abnormal mitoses, a raised mitotic count (at least 11 per 50 high power fields) and broad fibrous bands (Fig. 1A-C). The Weiss score was therefore 6 out of 9 , thereby securing the diagnosis of adrenal cortical carcinoma [8, 9]. The Ki-67 index was $44.1 \%$. There was no capsular, sinusoidal or vascular invasion. The findings were those of an adrenal cortical adenocarcinoma (pT2 NX MX) [10, 11]. Immunohistochemistry with a mouse monoclonal antibody against human aromatase (Novartis clone \#677) [12] showed most, although not all, carcinoma cells to stain positively. Within the positively staining carcinoma cells, the labeling was diffuse or finely granular within the cytoplasm (Fig. 1D). Of particular note were densely staining cytoplasmic aggregates or "inclusions" of various sizes and shapes observed within many of the positive carcinoma cells (Fig. 1D and E). Aromatase 

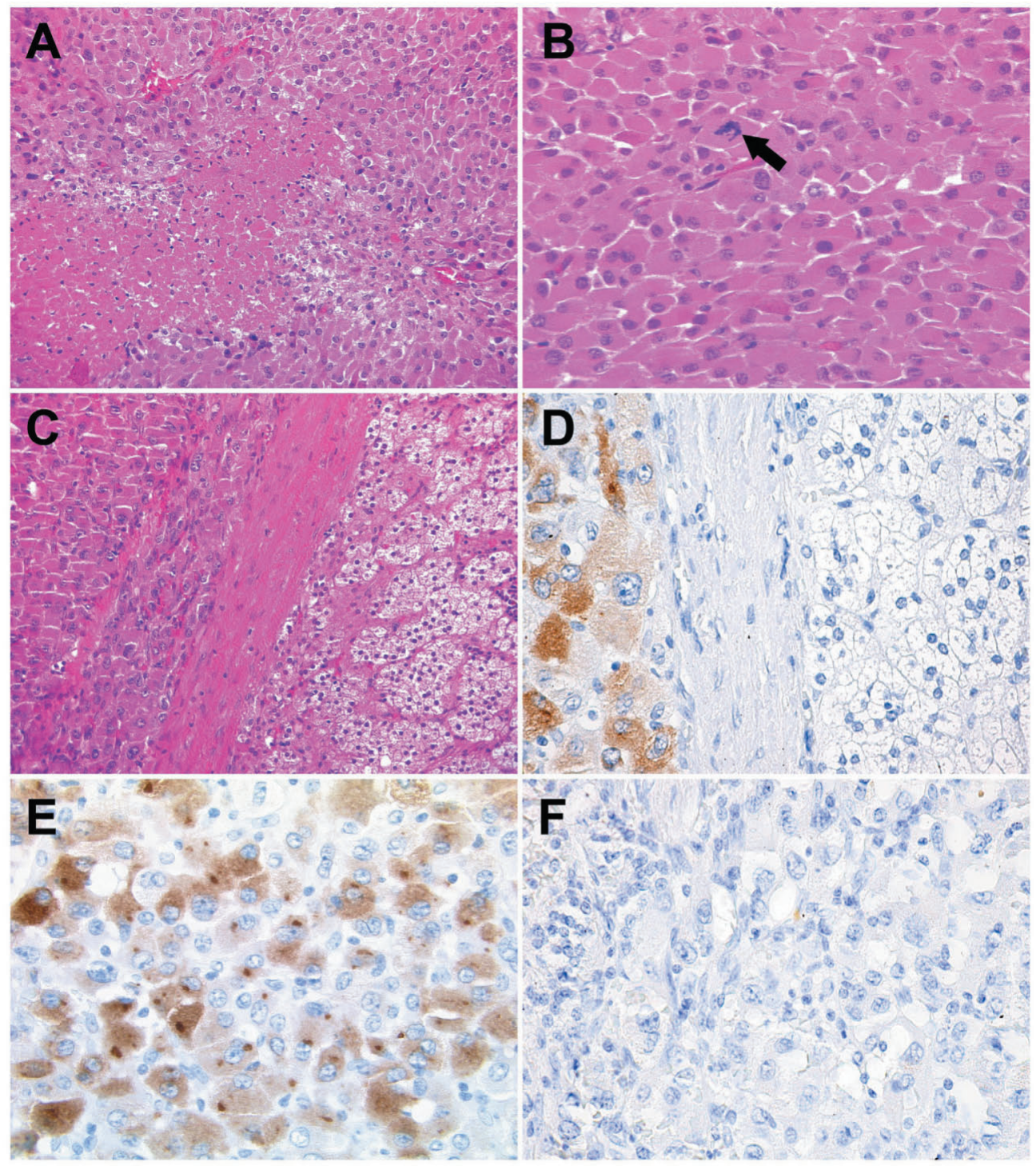

G

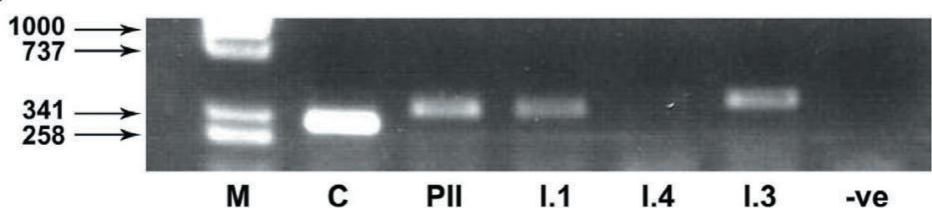

Fig. 1 Histochemical and immunohistochemical staining of the estrogen-secreting adrenal adenocarcinoma. Figure 1A H\&E stained section of the carcinoma showing diffusely arranged large eosinophilic epithelial cells with an area of confluent necrosis (original magnification x200). Figure 1B H\&E stained section of the carcinoma demonstrating large eosinophilic epithelial cells with pleomorphic nuclei and an abnormal mitotic figure (arrow) (original magnification x400). Figure 1C H\&E stained section showing the carcinoma (left), its capsule (centrally) and adjacent normal adrenal cortex (right) (original magnification x200). Figure 1D Immunohistochemistry for aromatase showing positive staining in carcinoma cells, but not in the adjacent normal adrenal (original magnification $\mathrm{x} 400$ ). Figure 1E Immunohistochemistry for aromatase within the cytoplasm of positively staining carcinoma cells (original magnification $\mathrm{x} 400$ ). Figure $1 \mathrm{~F}$ Negative (isotype $\mathrm{IgG}$ ) control (original magnification $\mathrm{x} 400$ ). Figure $1 \mathrm{G}$ PCR amplification of aromatase (CYP19) transcripts in the adrenal carcinoma. After reverse transcription complementary DNA samples were amplified using primers specific for the various CYP19 gene transcripts. $\mathrm{M}=$ size markers, size of fragments is shown in bp; $\mathrm{C}=$ coding region; $\mathrm{PII}=$ promoter II specific region; I.1=exon I.I; I.4=exon I.4 and I.3=exon I.3. The -ve was a PCR control. 
Table 2 Urine steroid profiles pre- and post-operatively.

\begin{tabular}{|c|c|c|c|c|}
\hline \multirow{2}{*}{ Steroid $(\mu \mathrm{g} / 24 \mathrm{~h})$} & \multirow{2}{*}{ Pre-operative } & \multirow{2}{*}{ Post-operative } & \multicolumn{2}{|c|}{ Normal adult male $(\mathrm{n}=20)$} \\
\hline & & & Mean & SD \\
\hline \multicolumn{5}{|l|}{$5 \alpha$-series } \\
\hline Androsterone & 206 & 1356 & 1526 & 520 \\
\hline $11 \beta-\mathrm{OH}$-Androsterone & 434 & 734 & 855 & 244 \\
\hline Allo-Tetrahydrocortisol & 1303 & 1381 & 1205 & 509 \\
\hline \multicolumn{5}{|l|}{$5 \beta$-series } \\
\hline Aetiocholanolone & 1173 & 1033 & 1308 & 565 \\
\hline $11 \beta-\mathrm{OH}$-Aetiocholanolone & 662 & 435 & 545 & 496 \\
\hline Tetrahydrocortisol & 2795 & 900 & 1275 & 481 \\
\hline
\end{tabular}

immunoreactivity was not observed in stromal cells of the adrenal gland. The aromatase transcripts associated with utilization of the gonadal-associated aromatase promoter II were prominently represented in the tumor aromatase mRNA. However, significant amounts of transcripts associated with both promoters I.1 and I.3 were observed, while there was no evidence for promoter I.4-associated activity (Fig. 1G).

Urine steroid profiles pre-operatively showed an increase in $5 \beta$-relative to $5 \alpha$-reduced metabolites and of pregnanediol, pregnenetriol and a number of unusual additional metabolites suggestive of steroid production by the adrenal mass (Table 2). Post-operatively, the relative excesses previously noted were no longer present and the ratio of $5 \beta$ - to $5 \alpha$-reduced steroids was reversed with relatively higher levels of $5 \alpha$-reduced steroids, consistent with the increased levels normally found in adult males compared to females [13].

Post-operatively, gynecomastia regressed and libido improved, accompanied by normalization of all biochemical parameters (Table 1). Three years later there is no clinical, radiological or endocrine evidence of recurrent disease.

\section{Discussion}

Estrogen-secreting adrenal tumors are an uncommon cause of gynecomastia and are almost invariably malignant [14]. Feminizing symptoms are attributed to the in situ generation of $\mathrm{E}_{1}$ through aberrant aromatisation of adrenal androgens with trivial or no estrogen secretion occurring in normal adrenals [15]. Our patient's pre-operative endocrine profile was charac- teristic of that of an estrogen-secreting tumor with increased circulatory levels of $E_{1}$ and $E_{2}$, low serum testosterone and gonadotropins and a moderately elevated serum 11-deoxycortisol. Suppressed gonadotropin secretion is a recognized consequence of aromatization of testosterone to $\mathrm{E}_{2}$ [16], demonstrating that even in men gonadotropin secretion is predominantly under estrogen-mediated feedback inhibition. Increased serum 11-deoxycortisol suggests impaired $11 \beta$-hydroxylase activity within the tumor. Although decreased $11 \beta$-hydroxylase activity is a characteristic feature of feminizing adrenocortical adenocarcinomas $[4,15,17]$, it is unclear whether this is a consequence of estrogen excess or a direct effect of the neoplastic process.

Even though the patient was normotensive without Cushingoid features, the abnormal cortisol dynamics illustrate the importance of actively seeking evidence for autonomous cortisol secretion in all patients presenting with feminizing adrenocortical carcinomas. Patients with tumorous adrenal cortisol hypersecretion can develop cardiovascular collapse post-adrenalectomy, due to "suppression" of the contralateral normal adrenal gland, unless peri- and post-operative glucocorticoids are administered. In the setting of a low serum testosterone, the absence of supranormal levels of LH and FSH was suggestive of hypogonadotropic hypogonadism, although unequivocal diagnosis would have required a GnRH stimulation test.

Aromatase mRNA has been previously demonstrated in feminizing adrenal tumors $[7,17]$. However, the presence of biologically active translated protein has typically been assumed, based on the detection of aro- 
matase activity by the tritiated water technique, even though aromatase activity in adrenocortical adenocarcinoma is approximately 50 -fold lower than that found in human placenta $[4,17]$. In the present report, we demonstrated the distribution of the translated aromatase protein within an adrenal tumor, the feminizing features and endocrinological presentation of the patient serving as an indicator that the immunoreactive aromatase was biologically functional. Under normal conditions, aromatase is located in the endoplasmic reticulum of estrogen producing cells [18]. In our patient, cellular immunostaining was heterogeneous. In positive cells, immunostaining was diffuse or finely granular within the cytoplasm, with additional immunopositive inclusions or aggregates.

The site-specific expression of aromatase is regulated by tissue-specific promoters: proximal promoter II in ovary, distal promoter I.1 in placenta and promoters I.3 and I.4 in adipose tissue [5]. Promoter II is proximal to the translation start site and is considered to be the primitive promoter regulating estrogen expression. As has been shown in adrenocortical tumors [19], and others, promoter II was prominent for the pathological aromatase expression in our patient. However, transcripts derived from promoters I.1 and I.3 were also detectable. While promoter I.3 transcripts have been previously reported in adrenal tumors, to our knowledge this is the first report of adrenal tumor aromatase expression utilizing the so-called 'placental' promoter, which occurred in the absence of placental tissue within the tumor.

Although serum estrogens were elevated, the $\mathrm{E}_{1}: \mathrm{E}_{2}$ ratio was approximately one. In the context of low pre-operative peripheral testosterone levels, it has previously been suggested that $E_{2}$ production originates from peripheral $\mathrm{E}_{1}$ conversion via $17 \beta$-hydroxysteroid dehydrogenase type 1 (17HSD1) [7, 17]. However, we recently showed that adrenal cancer cells express the reductive type $517 \beta$-hydroxysteroid dehydrogenase (AKR1C3) which is capable of converting $E_{1}$ to $\mathrm{E}_{2}$ as well as androstenedione to testosterone, indicating the capacity for direct $\mathrm{E}_{2}$ production by the tumor [12]. Locally synthesized estrogens may promote cellular proliferation in aromatase expressing female breast carcinomas [20, 21]. Although we did not measure receptor activity, estrogen receptor $\beta$ expression has previously been reported in a steroid-producing adrenocortical cell line [22]. Accordingly, it is possible that estrogens produced by the adrenal carcinoma cells may have contributed to the high rate of cellular proliferation observed in our patient.

In summary, although estrogen-secreting adrenocortical carcinomas are extremely rare, there are now sufficient data to indicate how aberrant aromatase expression can result in a characteristic clinical and biochemical presentation. The diagnosis should be considered in all patients presenting with hypogonadotropic hypogonadism, particularly if there is also gynecomastia.

\section{Acknowledgements}

The authors gratefully acknowledge the assistance of the nursing staff of the Programmed Investigations Unit and the laboratory staff of the Clinical Biochemistry Department at The Newcastle upon Tyne NHS University Hospital Foundation Trust, Newcastle upon Tyne, UK and the Newcastle Supra Regional Assay Service (SAS) for Endocrinology.

\section{References}

1. Allolio B, Fassnacht M (2006) Clinical review: Adrenocortical carcinoma: clinical update. J Clin Endocrinol Metab 91:2027-2037.

2. Advani A, Vaikkakara S, Gill MS, Arun CS, Pearce SH, Ball SG, James RA, Lennard TW, Bliss RD, Quinton R, Johnson SJ (2008) Impact of standardised reporting in adrenocortical carcinoma: a single centre clinicopathological review. J Clin Pathol 61:939-944.

3. Gabrilove JL, Sharma DC, Wotiz HH, Dorfman RI (1965) Feminizing Adrenocortical Tumors in the Male. A Review of 52 Cases Including a Case Report.
Medicine (Baltimore) 44:37-79.

4. Kimura M, Itoh N, Tsukamoto T, Kumamoto Y, Takagi Y, Mori Y (1995) Aromatase activity in an estrogenproducing adrenocortical carcinoma in a young man. $J$ Urol 153:1039-1040.

5. Simpson ER, Mahendroo MS, Means GD, Kilgore MW, Hinshelwood MM, Graham-Lorence S, Amarneh B, Ito Y, Fisher CR, Michael MD, et al. (1994) Aromatase cytochrome P450, the enzyme responsible for estrogen biosynthesis. Endocr Rev 15:342-355.

6. Hemsell DL, Edman CD, Marks JF, Siiteri PK, 
MacDonald PC (1977) Massive extranglandular aromatization of plasma androstenedione resulting in feminization of a prepubertal boy. J Clin Invest 60:455-464.

7. Phornphutkul C, Okubo T, Wu K, Harel Z, Tracy TF, Jr., Pinar H, Chen S, Gruppuso PA, Goodwin G (2001) Aromatase $\mathrm{p} 450$ expression in a feminizing adrenal adenoma presenting as isosexual precocious puberty. $J$ Clin Endocrinol Metab 86:649-652.

8. Weiss LM (1984) Comparative histologic study of 43 metastasizing and nonmetastasizing adrenocortical tumors. Am J Surg Pathol 8:163-169.

9. Weiss LM, Medeiros LJ, Vickery AL, Jr. (1989) Pathologic features of prognostic significance in adrenocortical carcinoma. Am J Surg Pathol 13:202-206.

10. Macfarlane DA (1958) Cancer of the adrenal cortex; the natural history, prognosis and treatment in a study of fifty-five cases. Ann R Coll Surg Engl 23:155-186.

11. Sullivan M, Boileau M, Hodges CV (1978) Adrenal cortical carcinoma. J Urol 120:660-665.

12. Nicol MR, Papacleovoulou G, Evans DB, Penning TM, Strachan MW, Advani A, Johnson SJ, Quinton R, Mason JI (2009) Estrogen biosynthesis in human H295 adrenocortical carcinoma cells. Mol Cell Endocrinol 300:115-120.

13. Raven PW, Taylor NF (1996) Sex differences in the human metabolism of cortisol. Endocr Res 22:751-755.

14. Fassnacht M, Kenn W, Allolio B (2004) Adrenal tumors: how to establish malignancy? J Endocrinol Invest 27:387-399.

15. McKenna TJ, O’Connell Y, Cunningham S, McCabe M, Culliton M (1990) Steroidogenesis in an estrogenproducing adrenal tumor in a young woman: comparison with steroid profiles associated with cortisol- and androgen-producing tumors. J Clin Endocrinol Metab 70:28-34.

16. Santen RJ (1975) Is aromatization of testosterone to estradiol required for inhibition of luteinizing hormone secretion in men? J Clin Invest 56:1555-1563.

17. Young J, Bulun SE, Agarwal V, Couzinet B, Mendelson CR, Simpson ER, Schaison G (1996) Aromatase expression in a feminizing adrenocortical tumor. J Clin Endocrinol Metab 81:3173-3176.

18. Ma CX, Adjei AA, Salavaggione OE, Coronel J, Pelleymounter L, Wang L, Eckloff BW, Schaid D, Wieben ED, Weinshilboum RM (2005) Human aromatase: gene resequencing and functional genomics. Cancer Res 65:11071-11082.

19. Bouraima H, Lireux B, Mittre H, Benhaim A, Herrou M, Mahoudeau J, Guillon-Metz F, Kottler ML, Reznik Y (2003) Major hyperestrogenism in a feminizing adrenocortical adenoma despite a moderate overexpression of the aromatase enzyme. Eur J Endocrinol 148:457-461.

20. Sasano H, Harada N (1998) Intratumoral aromatase in human breast, endometrial, and ovarian malignancies. Endocr Rev 19:593-607.

21. Moreau F, Mittre H, Benhaim A, Bois C, Bertherat J, Carreau S, Reznik Y (2009) Aromatase expression in the normal human adult adrenal and in adrenocortical tumors: biochemical, immunohistochemical, and molecular studies. Eur J Endocrinol 160:93-99.

22. Montanaro D, Maggiolini M, Recchia AG, Sirianni R, Aquila S, Barzon L, Fallo F, Ando S, Pezzi V (2005) Antiestrogens upregulate estrogen receptor beta expression and inhibit adrenocortical H295R cell proliferation. J Mol Endocrinol 35:245-256. 